\section{Memória e História da Comunicação: a participação da Associação Brasileira de Imprensa (ABI) no processo de profissionalização do jornalista}

Hérica LENE ${ }^{1}$

Resumo: Resgatar a participação da Associação Brasileira de Imprensa (ABI), criada em 1908, como instituição estimuladora da profissionalização e valorização da profissão de jornalista no país é o principal objetivo desta abordagem. As opções metodológicas foram: pesquisa bibliográfica e análise documental. As principais fontes de pesquisa foram o livro $A$ trincheira da liberdade - bistória da $A B I$, do jornalista Edmar Morel, publicado há 27 anos, a partir dos relatos e registros de seus presidentes; a edição comemorativa do Jornal da $A B I$ do centenário da instituição; e os textos veiculados no site oficial da associação, com relatos e o discurso oficial da ABI. Buscamos como principais aportes teóricos os conceitos de memória de Maurice Halbwachs (1990), Pierre Nora (1993) e Michel Pollak (1989); sobre história da imprensa no país de Nelson Werneck Sodré (1999), Juarez Baia (2009), Marialva Barbosa (2000; 2010) e Ana Paula Goulart Ribeiro (2007); e os estudos sobre a profissão de Nelson Traquina (2004).

Palavras-chaves: Comunicação; Memória e história da imprensa; Associação Brasileira de Imprensa - ABI; Jornalismo; Profissionalização.

\section{Memoria e Historia de la Comunicación: la par-} ticipación de la Asociación Brasileña de Prensa

1 Jornalista, doutora em Comunicação e Cultura pela UFRJ (2009), mestre em Comunicação pela UFF (2004) e professora do curso de Comunicação da Universidade Federal do Recôncavo da Bahia (UFRB). E-mails: hericalene@yahoo.com.br e hericalene@pesquisador.cnpq.br.
(ABI) en el proceso de profesionalización de los periodista

Resumen: Canjear la participación de la Asociación Brasileña de Prensa (ABI), creada en 1908 como una institución de estimular la recuperación y la profesionalización del periodismo en el país es el objetivo principal de este enfoque. Las opciones metodológicas fueron: revisión bibliográfica y análisis de documentos. Las principales fuentes de investigación fueron el libro La libertad trinchera - historia de ABI, el periodista Edmar Morel, publicado hace 27 años, a partir de las cuentas y los registros de sus presidentes, la edición conmemorativa del centenario de la institución Diario ABI, y textos que se presentan en la web oficial de la asociación, con los informes y el discurso oficial de la ABI. Nicer como marco teórico principal de los conceptos de memoria de Maurice Halbwachs (1990), Pierre Nora (1993) y Michel Pollak (1989), acerca de la historia de la prensa en el país de Nelson Werneck Sodré (1999), Juárez Bay (2009), Barbosa Marialva $(2000,2010)$ y Ana Paula Ribeiro Goulart (2007), y estudios de la profesión Traquina Nelson (2004).

Palabras-clave: Comunicación; La memoria y la historia de la prensa; Asociación Brasileña de Prensa - ABI; Periodismo; Profesionalización.

\section{Introdução}

O jornalismo começa a ganhar a forma como campo nas sociedades ocidentais no século XIX. Esse processo vai se dar com o desenvolvimento do capitalismo e de outras mudanças que incluem a industrialização, a urbanização, a educação de massa, o progresso tecnológico e a emergência da imprensa como mass media.

Foi durante a modernidade que as notícias tornaram-se simultaneamente um gênero e um serviço; o jornalismo tornou-se um negócio e um elo vital na teoria democrática; e os jornalistas ficaram empenhados em um processo de profissionalização que procurava maior autonomia e estatuto social (TRAQUINA, 2005, p. 20).

A criação de associações e sindicatos fez parte do processo de legitimação e do fortalecimento do jornalismo como profissão e começou a partir da segunda metade do século XIX, nos Estados Unidos e na Europa. A profissionalização envolveu também a criação de cursos universitários e instituição de códigos deontológicos ${ }^{2}$ (T'RAQUINA, 2004, p.81 e 92).

No Brasil, foi criada a Associação Brasileira de Imprensa (ABI), na primeira década do século $\mathrm{XX}$, no Rio de Janeiro. O objetivo deste artigo é justamente abor-

2 Nos Estados Unidos, por exemplo, foi criado o Washington's Correspondents Club, na capital, Washington, organizado em 1867 (TRAQUINA, 2004, p.81). 
dar a participação dessa instituição na profissionalização e valorização do jornalista: como ela contribuiu para a consolidação da profissão e no jornalismo enquanto campo no país?

Esta abordagem ${ }^{3}$ foi desenvolvida a partir de pesquisa bibliográfica e análise documental que, por sua vez, compreendeu a identificação e a verificação de pesquisas existentes sobre a ABI, funcionando como expediente eficaz para contextualizar fatos, situações, momentos. As fontes, nesse caso, foram de origem secundária: constituíram conhecimento, dados ou informação já reunidos ou organizados por outro pesquisador (MOREIRA, 2005, p. 269-279).

As principais fontes de pesquisa foram o livro $A$ trincheira da liberdade - história da ABI, do jornalista Edmar Morel, publicado há 27 anos, a partir dos relatos e registros de seus presidentes; a edição comemorativa do Jornal da $A B I$ do centenário da instituição; e os textos veiculados no site oficial da associação, com relatos e o discurso oficial da ABI.

Os relatos de agentes participantes são fundamentais para ajudar a resgatar a memória e a história da instituição. Em uma abordagem anterior sobre a questão da memória (LENE, 2010), citamos Maurice Halbwachs (1990), que diz que as lembranças, apesar de pertencerem aos indivíduos, se originam na sociedade. Os sujeitos só lembram a partir do ponto de vista de um grupo social específico, ao qual de alguma forma se vinculam. Já Pierre Nora (1993) destaca que memória é experiência vivida, configurada pela dialética lembrança e esquecimento, lugares de disputas, conflitos, na busca incessante por sentidos coerentes e unívocos.

Michel Pollak (1989) afirma que a memória é um processo de ordenamento, de produção de sentido, que pressupõe enquadramentos, esquecimentos e silêncios. Fatos e aspectos do passado são recordados e enfatizados a partir da relevância que eles têm para os indivíduos que recordam pela sua contribuição na construção da identidade e das relações pessoais.

O ponto de partida de qualquer ato mnemônimo é o presente. A memória, por ser essencialmente discurso, é sempre contextual e dialógica. A sua organização está ligada a processos de seleção e enquadramento, resul-

3 Integra as atividades do projeto Memória e História da Imprensa, desenvolvido com o apoio do CNPq e coordenado pela autora. Além de estudos sobre área, inclui também a atualização de uma base de dados on-line (www.memoriadaimprensa.com.br). tantes de conflitos e negociações que os sujeitos travam em situações sociais concretas. ${ }^{4}$

Assim, os relatos dos ex-presidentes da ABI fazem um processo de ordenamento dos principais fatos que eles consideram como importantes para a construção da história da instituição.

\section{O surgimento da ABI e os "proletários intelectu- ais"}

A criação da ABI, na primeira década do século $\mathrm{XX}$, foi uma consequência das transformações da imprensa dentro do contexto histórico daquele início de século. A fase compreendida entre o último quartel do século XIX e o início do seguinte é considerada por historiadores, como Tania Regina de Luca (2008, p.149), como um período de inflexão na trajetória da imprensa brasileira.

Naquele momento, a produção artesanal dos impressos, graças à incorporação dos avanços técnicos, começou a ser substituída por processos de caráter industrial, marcados pela especialização e divisão do trabalho no interior da oficina gráfica e a conseqüente diminuição da dependência de habilidades manuais. Máquinas modernas de composição mecânica e rotativas cada vez mais velozes alteraram o processo de compor e reproduzir textos e imagens, e passaram a ser utilizadas pelos periódicos de algumas das principais capitais brasileiras.

Se, por várias décadas, a luta política constitui-se no motor fundamental do jornal, o foco passou a ser o negócio, em busca de aumento de tiragem e do número de páginas e da oferta de uma mercadoria mais atraente.

Esse contexto foi marcado pelo final da escravidão, instauração do regime republicano e seu ideal de reformar o ensino e disseminar o letramento, prosperidade

4 Inúmeros autores se ocuparam nos últimos 100 anos em tecer esse conceito em toda a sua complexidade: desde os estudos pioneiros de Freud, passando pela conceituação de Bérgson; a percepção de memória na sua dimensão social realizada por Maurice Halbawchs, a partir de sua polêmica com o fundador da École dês Analles, Marc Bloch, construída no seu primeiro e segundo sistemas; sem falar em outros pesquisadores que mais recentemente não deixaram de se referir à memória, acrescentando outros postulados fundamentais. Neste sentido, há que se destacar a obra de Pierre Nora e seu conceito polêmico e, ao mesmo tempo, desafiador, de "lugares de memória"; os estudos de Michel Pollack; as aproximações entre memória e identidade, realizadas por Gérard Namer e Jöel Candau; as reflexões em torno da relação memória e poder, das memórias silenciadas e esquecidas em contraposição às memórias publicizadas e oficializadas, realizadas por Jacques Le Goff, Georges Duby e Andréas Huyssen, entre tantos outros (BARBOSA, 2005, p.107-108). 
trazida pelo café, crescimento dos centros urbanos e do setor de serviços, com particular destaque para o Rio de Janeiro e São Paulo (LUCA, 2008, p. 150).

É nesse bojo de transformações que surge a ABI. Conforme registrou Nelson Werneck Sodré (1999, p.307), a organização que visaria agrupar os jornalistas decorreu do desenvolvimento da imprensa, da importância que ela conquistara e das novas condições que se apresentavam, peculiares à imprensa industrial, nas grandes cidades. "Atingida a etapa da grande imprensa, estabelecida esta em moldes capitalistas, surgiria, necessariamente, a organização agrupadora dos que nela trabalhavam, os profissionais, os jornalistas" (Ibid.).

A ABI foi criada a partir da iniciativa do jornalista Gustavo de Lacerda, que convidou outros oito profissionais de imprensa para a fundação da entidade. Surgiu tendo como bandeira principal a defesa da liberdade. E esse tem sido seu discurso legitimador de uma instituição que pretendeu, ao longo de sua história, não se limitar a ser uma entidade de assistência aos jornalistas.

Nos 104 anos de sua existência, cerca de um terço decorreu em um ambiente de frustração dos direitos civis e de sonegação da liberdade de imprensa e dos direitos que a integram: o de informar, o de acesso às fontes de informação, o de opinar e, neste, o de discordar, de dizer não. Estes direitos foram ressaltados pelo jornalista e jurista Prudente de Morais, na época em que foi presidente da ABI (gestão de 1975 a 1977).

Foram quatro anos do mandato do presidente da República Artur Bernardes (1922-1926), que governou praticamente sob estado de sítio, os oito anos do Estado Novo (1937-1945) e os 21 anos da ditadura militar (19641985). Como registrou o atual presidente da ABI, Maurício Azêdo, na edição especial do Jornal da ABI em comemoração ao centenário da entidade, em abril de 2008, a ABI atuou como defensora dos direitos dos jornalistas e dos veículos de comunicação, submetidos não apenas à censura, mas à privação da liberdade, da integridade física e, em numerosos casos, da vida.

Sobre essa data comemorativa, escreveu Maurício Azêdo:

A ABI pode proclamar o seu orgulho de ter servido ao país nos diferentes campos em que teve ensejo de atuar: na elevação do padrão técnico, ético e cultural do jornalismo brasileiro, na defesa do melhor interesse nacional, expresso sobretudo no estímulo à criação da histórica campanha $O$ petróleo é noss $0^{5}$, na exaltação da democracia na melhor forma para a convivência social e a solução de conflitos (AZÊDO, 2008, p.12).

A principal bandeira da ABI sempre foi a liberdade de imprensa. A questão é, aliás, de maneira geral, muito cara a jornalistas de diferentes perfis. Trata-se, conforme destaca Ana Paula Goulart Ribeiro (2007, p. 310), de um importante elemento na construção da identidade profissional. Em diferentes conjunturas da história do País, a Associação procurou defender a pessoa do jornalista, intercedendo por ocasião de prisões e inquéritos abertos contra profissionais. Nos seus boletins, sempre havia denúncias de fechamento de jornais e agressões a jornalistas.

Durante a ditadura militar, a ABI denunciou várias atos de violência praticados contra jornalistas e os veículos de comunicação. A entidade assumiu um papel de trincheira na reconquista dos direitos da imprensa.

A história da fundação da ABI se confunde com a de seu idealizador, o jornalista catarinense Gustavo de Lacerda. Criada em 7 de abril de 1908, seu principal objetivo era assegurar à classe jornalística os direitos assistenciais e tornar-se um centro poderoso de ação. Segundo o próprio Lacerda, a Associação deveria ser um campo neutro em que se pudessem abrigar todos os trabalhadores da imprensa.

Em uma pequena sala na sobreloja do imóvel onde funcionava a Caixa Beneficente dos Empregados do jornal O Paín, Lacerda se reunia com outros colegas de redação para discutir sobre a instituição de classe que pretendiam fundar. Gustavo de Lacerda, Mário Galvão e Amorim Júnior foram incumbidos da elaboração do primeiro projeto de estatuto da ABI.

Socialista convicto, Lacerda não concordava com a ideia de que os jornais fossem empresas, dando lucro a seus acionistas. Para ele, deveriam ter uma missão social

5 Foi na sede da ABI que se realizaram as reuniões patrióticas que antecederam a Lei de 1953, que instituiu a Petrobras. Na noite de $1^{\circ}$ de agosto de 1988, parlamentares de várias tendências, intelectuais, representantes de entidades da sociedade civil e centenas de populares lotaram o auditório da Associação, em uma manifestação em defesa do monopólio estatal do petróleo, contra os contratos de risco e pela nacionalização das riquezas minerais do país. O ato foi presidido por Barbosa Lima Sobrinho. Cf. "Fatos que marcaram a história da ABI" no site oficial: http://www.abi.org.br/ paginaindividual.asp?id=1577. Disponível em 11 de janeiro de 2012. 
e funcionar como cooperativas de cujos interesses participassem todos os seus membros, dos diretores aos mais modestos colaboradores.

Ele lutava "pela transformação do panorama econômico e moral dos proletários intelectuais", como denominava os jornalistas. Participou dos primeiros movimentos operários de alguma importância ocorridos no Rio de Janeiro, foi um dos animadores do Centro Operário Radical, que funcionou no Rio por volta de 1892, e participou como colaborador do programa dessa entidade, abordando o problema da reforma agrária e do combate aos privilégios e monopólios (SODRÉ, 1999, p. 308). ${ }^{6}$ Era a fase das resistências dos operários, organizações de união e defesa dos trabalhadores.

No programa de fundação da ABI Lacerda expôs reivindicações que só apareceriam na Revolução de 1930. É dele a ideia de manter uma biblioteca aberta ao público, com o objetivo de atender não apenas às necessidades de informação cultural dos jornalistas, mas também à população da cidade do Rio de Janeiro.

Após a criação da associação, coube à primeira Diretoria a função de consolidar e ampliar a iniciativa, mesmo com muitas dificuldades. Os fundadores eram tratados como indesejáveis e muitos esforços foram empreendidos com o objetivo de vencer o descaso e a hostilidade por parte de dirigentes de veículos de comunicação. A ABI era composta, segundo alguns céticos da época, por um grupo de malandros chefiados por um anarquista perigoso (Lacerda).

Naquele momento, o meio jornalístico encontrava-se disperso e, portanto, desfavorável a qualquer ideal de solidariedade profissional. Mas em busca de autodefesa e de prestigiar a classe à qual pertenciam, os homens de imprensa foram aderindo à entidade e o prestígio da instituição, consolidando o sonho de Lacerda, que se deu com a inscrição no quadro social da Casa de nomes representativos na vida nacional, como o chefe da Polícia, o comandante da Polícia Militar, o prefeito, o comandante do Corpo de Bombeiros e o ministro da Guerra.

Gustavo de Lacerda representa um dos ícones da ABI e também da categoria pela iniciativa de criar uma instituição que cuidasse dos direitos dos jornalistas. Como ressalta Traquina (2004, p.51), a cultura jornalística é rica em mitos, símbolos e representações sociais que fornecem a essa comunidade interpretativa toda uma li-

6 Lacerda publicou, em 1901, o opúsculo de propaganda socialista $O$ Problema do Operário no Brasil (SODRÉ, 1999, p. 308). turgia de figuras bem claras dos vilões e dos heróis a que os membros dessa comunidade prestam homenagem ou devotam ódio.

A mitologia jornalística coloca os membros dessa comunidade profissional no papel de: servidores do público que procuram saber o que aconteceu; no de "cães de guarda" que protegem os cidadãos contra os abusos do poder; no de "Quarto Poder" que vigia os outros poderes, atuando doa a quem doer e, por isso, importante para o sistema democrático (TRAQUINA, 2004, p.51).

Segundo a cultura profissional, essa comunidade é de crentes que cumpre o serviço em uma dedicação total à profissão, cujo lado sagrado envolve: longas e irregulares horas de trabalho em que deixa de haver uma distinção entre a esfera da vida privada e a profissional, os evidentes perigos que os profissionais possam enfrentar, incluindo o de vida, a natureza altruística (devoção ao próximo) e mesmo nobre das suas responsabilidades sociais. Outros mitos que circulam na cultural profissional do jornalista são o do scoop (o furo) e o da "grande história" (TRAQUINA, 2004, p.53-55).

O próprio Lacerda encarnou esse papel do jornalista que não mede esforços pela profissão. Como registra Moacir Pereira (2008, p. 35): "Vivia apena da profissão, sendo que em $O$ Paíz a remuneração vinha quase sempre em forma de vales atrasados. Teve de buscar outras atividades para sobreviver. E, relatam todos os seus contemporâneos, teve um final trágico”.

Lacerda não foi um jornalista famoso, nem se valeu do trabalho na imprensa para galgar posições na política ou na administração pública, como era comum em seu tempo. No fim do Império e durante décadas após a proclamação da República, os jornais costumavam dividir as tarefas em castas, em que os repórteres exerciam atividades subalternas, sem o direito de assinaturas, enquanto os textos assinados eram privilégios dos donos dos jornais, dos políticos e, sobretudo, dos bacharéis que dominavam então as ciências humanas.

$\mathrm{O}$ fato que projetou Lacerda na vida pública brasileira foi mesmo o movimento pela criação da $\mathrm{ABI}$, fruto de sua pregação socialista, da batalha pela união dos repórteres visando à melhoria das condições de salário e de trabalho, do papel que vislumbrava na formação profissional por meio do processo educacional, e do desejo de ver os jornalistas mais protegidos e valorizados (PEREIRA, 2008, p. 35). 
Os objetivos da instituição constam dos estatutos, obra pessoal de Lacerda: criar e manter uma caixa de pensões e auxílios para os sócios e suas famílias; manter o serviço de assistência médica e farmacêutica; instalar o Retiro da Imprensa para os idosos; manter uma sede social no centro da cidade com biblioteca, salas de conferência; habilitar por meio de título de capacidade intelectual e moral os pretendentes ao título de jornalismo; instituir a Carteira de Jornalista.

Lacerda, aos 50 anos, era um homem doente. Sem trato e ganhando pouco, via chegar o fim da vida sem ter sua velhice assegurada. Meses após fundar a ABI, foi internado como indigente e por desnutrição na Santa Casa de Misericórdia. Como registra o jornalista Edmar Morel (1985, p.39-40): "O seu mal era incurável. Esperava recuperar a saúde, a exemplo das crises anteriores. A última, porém, teve palco a própria redação, onde o repórter caiu rolando pelas escadas. Era o começo do fim”.

Ele morreu no dia 4 de setembro de 1909, aos 56 anos, fato registrado por todos os principais jornais do Rio de Janeiro e com homenagens sempre ressaltando seu amor à profissão, sua luta pela unidade dos jornalistas e o fato marcante da fundação da ABI. Morel (1985, p. 45) ressalta: "Gustavo de Lacerda não tem rua, nem túmulo. Até a causa mortis foi deturpada. Arteriosclerose, nunca. A verdadeira foi: desnutrição, fome".

$\mathrm{O}$ vice-presidente da ABI na época, Francisco Souto, um dos dirigentes do Correio da Manhã, completou o mandato de Gustavo de Lacerda no período de setembro de 1909 a maio de 1910. A associação, nessa fase, não tinha prestígio porque quase todos os donos de jornais a sabotavam. O mérito de Souto foi impedir que ela sucumbisse por inanição.

O mandato seguinte foi de Dunshee de Abranches (de 1910 a 1913). Na sua gestão, conforme registram Morel (Ibid., p. 58) e Ribeiro (2007, p.309), foram implementadas as seguintes medidas, reivindicações do programa proposto por Gustavo de Lacerda: instituição da Carteira de Jornalista, que permitia a livre entrada em cinemas e espetáculos; regularização dos serviços médicos; criação dos fundos de assistência jurídica e funerais; e elaboração dos projetos da Escola de Jornalismo e do Anuário da Imprensa Brasileira,

No início da história da ABI, foram presidentes também os seguintes jornalistas: Belisário de Sousa (de 1913 a 1916, que renunciou antes do final do mandato); Raul Pederneiras (completou o mandato do antecessor e foi presidente em 1916 e 1917 e de 1920 a 1926); João Guedes Mello (de 1917 a 1918 e 1919 a 1920); Dario de Mendonça (de 1918 a 1919); Barbosa Lima Sobrinho (de 1926 a 1927; de 1930 a 1931 e teve ainda outros três mandatos pós-1964); Gabriel Bernardes (1927-1928); Manuel Paulo Filho (de 1928 a 1929); e Alfredo da Silva Neves (de 1929 a 1930).

Em 1931, quem assumiu a presidência foi Herbet Moses, que permaneceu no cargo por 33 anos e entrou para a história da ABI como o seu consolidador. Ele reformou as instalações da instituição na rua do Passeio para oferecer mais conforto aos associados.

Ao longo das duas primeiras décadas da existência da ABI - quando o Rio de Janeiro era ainda Capital da República -, a entidade acomodava-se em espaços alugados e, em tempos piores, sem condições de pagar aluguel, hospedou-se até no Quartel da Polícia Militar. Entre 1908 e 1942, passou por sete sedes. Só nos anos 1930 o sonho da sede própria se tornou realidade. Leis municipais de 1921 e 1922, não cumpridas, concederam terreno para edificação da sede própria (SODRÉ, 1999, p.309).

Ela foi construída sob a liderança de Herbert Moses, em terreno doado pelo prefeito Pedro Ernesto. O projeto, que representou um marco na arquitetura moderna brasileira, é de autoria dos irmãos Marcelo e Milton Ribeiro (RIBEIRO, 2007, p. 309). A sede definitiva, na rua Araújo Porto Alegre, $n^{\circ} 71$, foi posteriormente incorporada ao Patrimônio Artístico e Histórico do Brasil e leva o nome de Herbert Moses.

Depois de 1964, foram presidentes da ABI: Celso Kelly (de 1964 a 1966); Elmano Cruz (de fevereiro a maio de 1966 e de maio de 1974 a agosto de 1975); Danton Jobim (de 1966 a 1972 e fevereiro de 1978); Adonias Filho (de 1972 a 1974); Líbero de Miranda (de 27 de agosto a 6 de setembro de 1975); Prudente de Moraes Neto (de 1975 a 1977); Fernando Segismundo (de julho a setembro de 1976 e de dezembro de 1977 a fevereiro de 1978 e depois de 2000 a 2004); e Barbosa Lima Sobrinho (que já tinha sido em 1926-1927 e 1930-1931, ocupa novamente o cargo de 1978-1980, de 1980-1982 e de 1984-1986). ${ }^{7}$

Durante a ditadura militar, a ABI reativou a Comissão de Defesa da Liberdade de Imprensa, grupo criado por Herbert Moses, durante o Estado Novo, para proteger os jornalistas perseguidos pelo governo.

7 Cf. "Os presidentes" no site oficial da ABI: http://www.abi.org.br/ paginaindividual.asp?id=217. Disponível em 11 de janeiro de 2012. 
Apesar dos protestos e das críticas à repressão, as relações entre a $\mathrm{ABI}$ e o Estado foram preservadas, o que foi bastante contraditório para uma instituição que se arvorou em defesa da liberdade. Esta era, aliás, uma tradição da entidade. Seus líderes sempre mantiveram relações cordiais com o governo. Fato que lhe gerou muitas críticas. Herbert Moses, por exemplo, foi muito censurado por sua proximidade com Getúlio Vargas. Durante o Estado Novo, alguns conselheiros da ABI chegaram a exigir o seu rompimento com o presidente. ${ }^{8}$ Eles argumentavam que não era possível receber favores de um ditador que esmagava a liberdade de imprensa. Mas Moses era pragmático. Achava que aquela era uma tática legítima, que lhe possibilitava obter benefícios materiais para a entidade. Afirmava que, recebendo ou não auxílios oficiais, o governo não recuaria na repressão à imprensa. Além disso, ele poderia, dessa forma, manter canais abertos de negociação que lhe permitissem interceder por jornais e jornalistas perseguidos (RIBEIRO, 2007, p.311).

É interessante observar que uma instituição criada com a bandeira de luta pela liberdade mantivesse relações tão estreitas com o poder, na pessoa de seu presidente, mesmo nos períodos de supressão de liberdade. O objetivo do governo era a construção do consenso, o que, durante o Estado Novo, gerou a adesão por parte de jornais a seu projeto, com um processo de cooptação da imprensa, fundamental para a divulgação da mítica do novo Estado. ${ }^{9}$

Outro importante ícone da história da ABI foi Barbosa Lima Sobrinho, que lutava por ideais nacionalistas e via sua profissão como um meio de levar a população brasileira à conscientização política e social. Em 1926, aos 29 anos de idade, assumiu pela primeira vez a presidência da associação. Ele lutou pela unidade associativa, conseguindo incorporar outras entidades similares, como o Clube de Imprensa e a Associação de Imprensa Brasileira (RIBEIRO, 2007, p.309). Durante seu quarto mandato, em 1992, foi o responsável direto pelo pedido

8 Essas críticas se estenderiam ao período democrático. Durante o segundo governo Vargas, em agosto de 1952, Moses ofereceu na sede da ABI um almoço a Vargas e a seu ministro de Guerra, general Espírito Santo Cardoso, contando com a presença de mais de 40 generais. O episódio provocou muitos protestos, sobretudo da Tribuna da Imprensa. Carlos Lacerda, em um violento artigo, afirmou: "Se o sr. Moses está com fome e quer comer com Vargas, sirva-se, mas não em nosso nome" (MOREL, 1985).

9 Cf. Abordagem de Marialva Barbosa (2007) sobre "Imprensa e Estado Novo: o público como 'massa' (1930-1940)”. da abertura do impeachment de Fernando Collor de Mello e o primeiro orador inscrito para defender o processo. ${ }^{10}$

A ABI acabou por se constituir não apenas como um espaço de negociações e resistências, mas também como um lugar de sociabilidade, de encontro, de bate papo e de discussões. Em 1948, como registra Morel (1985, p.142), já funcionavam na sede nova da entidade, do $6^{\circ}$ ao $13^{\circ}$ andar, todos os seus serviços: a Clínica Pedro Ernesto (que tinha dez médicos), a administração, a biblioteca, o auditório (com capacidade para 800 pessoas), a discoteca, a sala-de-estar, o restaurante, o bar no terraço, a barbearia, o salão de leitura, bilhares, jogos de salão e, pouco tempo depois, também TV.

A Associação foi se fortalecendo nacionalmente. Em 1940 já contava com 3.880 sócios (MOREL, 1985). Ao longo do tempo foi se adaptando e ajustou seus estatutos às diversas situações socioeconômicas da indústria jornalística. ${ }^{11}$ Como disse Fernando Segismundo, em 1969:

\begin{abstract}
Além das finalidades fundamentais, a associação deve interpretar o pensamento, as aspirações, os reclamos, a expressão cultural e cívica de nossa imprensa; preservar a dignidade profissional dos jornalistas - e não apenas a de seus sócios; acautelar os interesses da classe; estimular entre os jornalistas o sentimento de defesa do patrimônio cultural e material da Pátria; realçar a atuação da imprensa nos fatos da nossa história; e colaborar em tudo que diga respeito ao desenvolvimento intelectual do País. ${ }^{12}$
\end{abstract}

Atualmente, de acordo com dados do site oficial da entidade, a ABI tem 8,3 mil associados. A diretoria está nas mãos de Maurício Azêdo desde maio de 2004. Ele está no terceiro mandato consecutivo (2010-2013). Nos

10 Em uma sessão do Conselho Administrativo da ABI, em outubro de 1992 - logo após ter sido aprovado o pedido de impeachment de Fernando Collor de Mello na Câmara dos Deputados -, Barbosa Lima Sobrinho, então presidente da Casa, relatou uma de suas viagens a Brasília, ocasião em que defendeu na Câmara o pedido de impeachment de Collor, juntamente com o então presidente da Ordem dos Advogados do Brasil, Marcelo Lavenère. Para Barbosa Lima Sobrinho, a atuação da imprensa no episódio situava-se entre as mais importantes, vigorosas e decisivas registradas na memória da Nação. Cf. "Fatos que marcaram a história da ABI" no site oficial: http:// www.abi.org.br/paginaindividual.asp?id=1577. Disponível em 11 de janeiro de 2012.

11 Cf. "Estatuto da ABI" no site oficial da entidade: http://www.abi. org.br/paginaindividual.asp? id=3632. Disponível em 11 de janeiro de 2012.

12 Cf. "História da ABI" no site oficial: http://www.abi.org.br/paginamenu.asp?id=8. Disponível em 11 de janeiro de 2012. 
anos 1970, ele foi o principal editor do antigo Boletim $A B I$, que se constituiu em um dos mais vigorosos e corajosos jornais de contestação do regime militar no campo das liberdades públicas, dos direitos civis e dos direitos humanos. ${ }^{13}$

Na gestão Prudente de Morais, neto, Azêdo liderou em 1975-1976 os trabalhos de reabertura e reorganização da biblioteca da ABI (Biblioteca Bastos Tigre), que havia sido fechada nos anos 1960, na gestão Celso Kelly, para locação do pavimento que ocupava, e seu acervo confinado em um cercado no saguão do $9^{\circ}$ andar do Edifício Herbert Moses e em desvãos entre pavimentos pouco usados.

Em 1976, quando a ABI era uma das entidades da sociedade civil que mais se destacava na defesa das liberdades democráticas, um ato terrorista destruiu todo o $7^{\circ}$ andar do edifício-sede da instituição, onde funcionavam o Conselho e os serviços administrativos e a Presidência. As autoridades nunca conseguiram identificar os autores do atentado a bomba. ${ }^{14}$

$\mathrm{Na}$ sede da ABI, em 1988, foi realizada a última reunião do Conselho Federal de Censura, liquidado pela nova Constituição. A despedida aconteceu na Sala Belisário de Souza, na tarde de 28 de setembro de 1988. No mesmo dia o presidente José Sarney assinou o decreto instituindo o Conselho de Defesa da Liberdade de Criação e de Expressão, para o qual foram designados representantes da ABI.

\section{Contribuições para a profissionalização e forma- ção do jornalista}

A ABI, por ser uma instituição voltada para a defesa dos jornalistas e da liberdade de imprensa (um dos valores mais importantes que compõem a cultura da profissão), é importante simbolicamente para o campo ${ }^{15}$ do

13 Além de promover em sucessivas edições a denúncia do assassinato do jornalista Vladimir Herzog nas masmorras do Doi-Codi do II Exército, em São Paulo, em 25 de outubro de 1975. o Boletim ABI divulgou em quatro páginas inteiras de uma edição em tamanho standard, em outubro de 1978, a íntegra da decisão em que o juiz Márcio José de Souza condenou a União a indenizar a viúva de Vlado, Clarisse Herzog, como responsável pela morte do jornalista. In: http://www. abi.org.br/paginaindividual.asp? $i d=190$. Acesso em 10 de janeiro de 2012.

14 Cf. "Fatos que marcaram a história da ABI" no site oficial: http:// www.abi.org.br/paginaindividual.asp? $i d=1577$. Disponível em $11 \mathrm{de}$ janeiro de 2012.

$15 \mathrm{O}$ conceito de campo foi fertilmente desenvolvido pelo sociólogo francês Pierre Bourdieu. Pode-se definir a modernidade como sendo a emergência de diferentes "campos": universos relativamente autô- jornalismo, para o processo de profissionalização dos jornalistas e para aquilo que Barbie Zelizer chamou de uma "comunidade interpretativa" ou que Michel Maffesoli, citado por Traquina (2004, p.24), chamou de "tribo".

Para Bourdieu (1997, p.19), o jornalismo é um microcosmos e os jornalistas partilham "estruturas invisíveis que organizam a percepção e determinam o que vemos e não vemos”. Escreve Bourdieu: “os jornalistas têm 'lentes' especiais através das quais vêem certas coisas e não vêem outras, e através das quais vêem as coisas que vêem da forma especial por que as vêem”.

No seu livro, $A$ sociologia das profissões, Philip Elliot (1972) aponta para a existência de "crenças comuns" e define a cultura do grupo como "sabedoria coletiva". Escreve Elliot (1972, p.131): “A adoção de uma identidade profissional tem um impacto no pensamento e no comportamento através do desenvolvimento de ideologias profissionais distintas".

O que é ser jornalista parte de toda uma cultura constituída por uma constelação de crenças, mitos, valores, símbolos e representações que constituem o ar que marca a produção das notícias. A identidade profissional, isto é, um ethos, é definida por uma maneira de como se deve ser (jornalista)/estar (no jornalismo), conforme ressalta Traquina (2004, p.37).

Nesse sentido, a ABI atuou como instituição simbolicamente estimuladora da profissionalização e da valorização da profissão de jornalista no País. Uma das ações foi a promoção de congressos e palestras para esses profissionais. Já em sua fundação, estava clara a preocupação com o ensino do jornalismo, bandeira que seria retomada no I Congresso Brasileiro de Jornalistas, iniciativa da $\mathrm{ABI}$, e que só se tornaria realidade em 1935, quando Anísio Teixeira instituiu a primeira cátedra de Jornalismo na Universidade do Distrito Federal, no Rio de Janeiro.

Foi durante o primeiro mandato de João Guedes Mello que foi promovido o I Congresso Brasileiro de Jornalistas, no dia 9 de setembro de 1918. Os participantes do evento, reunidos no Rio de Janeiro, no auditório da ABI, aprovaram moção endossando a proposta histórica de Gustavo de Lacerda para a criação de uma escola de jornalismo.

nomos de relações sociais. Para ele, a existência de um campo indica a existência de: 1) um “enjeu" ou prêmio que é disputado por agentes sociais diversos; 2) a existência de um grupo especializado que afirma possuir um monopólio de conhecimentos ou saberes especializados (TRAQUINA, 2005, p.17). 
A ABI tinha seu órgão oficial, o Boletim Mundial, com redação e administração com sede à rua 7 de Setembro, $n^{\circ} 145,1^{\circ}$ andar. Os números 32, 33 e 34 saíram dedicados exclusivamente ao congresso, instalado sob a presidência de honra do senador Fernando Mendes de Almeida, redator-chefe do Jornal do Brasil, decano dos jornalistas militantes (MOREL, 1985, p.82). Essa foi a primeira tentativa de unir nacionalmente os jornalistas.

Como parte do processo de fortalecimento da formação da categoria, João Guedes Mello estabeleceu a realização de palestras jornalísticas, "que eram assistidas sempre por elevado número de associados e eram proferidas por Azevedo Amaral, Carlos Fernandes, Júlio Lopes de Almeida, Pinto da Rocha e outros bons profissionais" (MOREL, 1985, p.81).

O processo de profissionalização dos jornalistas ganhou força a partir do Decreto-Lei no 910, de 30 de novembro de 1938. Ana Paula Goulart Ribeiro (2007, p.287), em uma pesquisa sobre a imprensa do Rio de Janeiro dos anos 1950, registra que, até o fim da República Velha, a imprensa contava com um número elevado de colaboradores semiprofissionais. Os jornalistas trabalhavam em vários órgãos ao mesmo tempo e, geralmente, em regime de freelancer. A situação começou a mudar a partir do Decreto, com o registro obrigatório dos jornalistas profissionais no Ministério do Trabalho.

$\mathrm{Na}$ época, existiam nos quadros redacionais dos jornais as funções de redator, repórter, auxiliar de repórter e revisor. Mais tarde, com o Decreto-Lei n ${ }^{\circ} 7.037$, de 10 de novembro de 1944, criaram-se também as categorias de repórter de setor, repórter auxiliar, noticiarista, redator-auxiliar, subsecretário e secretário e estabeleceram-se os salários mínimos para as diversas categorias (e uma hierarquia da profissão dentro das redações).

Apesar da legislação, os salários eram, em geral, pagos com atraso, predominando o sistema de vales. Mesmo com esses problemas, o jornalismo era uma profissão com um certo prestígio social. Muitas vezes era utilizada para ascensão social e obtenção de poder ou emprego público. Muitos indivíduos se aproveitavam do jornalismo apenas para - através do tráfico de influências - obter vantagens indiretas ou se iniciar na carreira política (RIBEIRO, 2007, p.288). ${ }^{16}$

16 Apesar dos baixos salários, os jornalistas gozaram de uma série de privilégios. O Decreto $\mathrm{n}^{\mathrm{O}} 3.590$, de 11 de janeiro de 1939, lhes concedeu transporte gratuito ou com desconto nas estradas de ferro da União. O Decreto $\mathrm{n}^{\circ} 4.144$, de 2 de março de 1942, expandia a isenção às viagens de navio. Com a Constituição de 1946, passaram a gozar de
Devido à má remuneração, a formação cultural dos profissionais, sobretudo dos repórteres, era em geral ruim. São comuns, tanto nas entrevistas como nos depoimentos da época, reclamações a respeito do baixo nível intelectual da maioria dos repórteres, que, apesar de dominarem as técnicas de apuração e investigação, não sabiam muitas vezes redigir. Havia, no entanto, uma elite de jornalistas bem preparados, geralmente formada nas Faculdades de Direito, mas a maioria não tinha sequer concluído o ensino médio (RIBEIRO, 2007, p.288-289).

A Faculdade de Direito, na República Velha, era a principal instância de produção ideológica, concentrando inúmeras funções políticas e culturais, e, não era de espantar que muitos jornalistas, principalmente dirigentes e acionistas dos jornais, eram egressos dessas academias (BARBOSA, 2000, p.80-81; 2010, p.149). Alguns eram oriundos também das escolas de Medicina e Engenharia. Sobre isso, registrou Marialva Barbosa:

Se os cursos de medicina e engenharia foram importantes na formação das elites, a formação jurídica era a preferida por quem pretendia se dedicar às letras, quer como crítico ou como escritores. O jornalismo funcionava como primeira porta para a carreira de escritor, mas, muitas vezes, as entradas subsequentes não podiam ser alcançadas e o bacharel perpetuavase na profissão, dividindo-a (...) com um cargo na burocracia oficial (BARBOSA, 2000, p.82).

A criação do ensino superior foi outro passo fundamental no processo de profissionalização dos jornalistas. Esta era uma reivindicação antiga de alguns jornalistas mais engajados. Quase sempre vinha associada a uma crítica ao mau preparo cultural e ético dos profissionais de imprensa. ${ }^{17}$

A ABI, como assinalado anteriormente, teve entre seus propósitos iniciais a criação de uma escola ou de um curso de preparação para jornalistas. A ideia, que não se concretizou logo no início, se manteve nas demais gestões. O caricaturista Raul Paranhos Pederneiras, que

muitas outras regalias, entre as quais a isenção fiscal. Além de não serem obrigados a declarar imposto de renda, eram isentos dos impostos predial e de transmissão. Tinham direito também a 50\% de desconto em passagens áreas e em casas de diversões públicas. Em janeiro de 1959, Juscelino Kubitschek sancionaria a lei n ${ }^{\circ} 3.529$, que garantia aos jornalistas profissionais aposentadoria especial após 30 anos de serviço (RIBEIRO, 2007, p.288).

17 Ribeiro (2007, p.292) registra que já em 1900 Theophilo Guimarães propunha a criação de uma escola de jornalismo. 
presidiu a Associação entre 1915 e 1917, afirmou, em seu relatório à Assembléia, que o estabelecimento da escola de jornalismo era uma necessidade concreta. Para ele, o nível do cultural do profissional seria muito superior se refinado em escola própria. Acabariam a "ignorância disseminada", a "má-fé" e os "processos indecorosos de fazer imprensa”, presumia ele.

Para Pederneiras, as escolas de jornalismo norte -americanas poderiam funcionar como modelos para as brasileiras. Nessa época, já funcionam, nos Estados Unidos, escolas de jornalismo junto às universidade de Missouri e Arizona, sendo famosa a que funcionava em Nova Iorque, anexa à Universidade de Columbia, criada por iniciativa de Joseph Pulitzer (RIBEIRO, 2007, p.292).

A proposta de fundar a escola de jornalismo é retomada, então, no I Congresso Brasileiro de Jornalistas. Como não seria oficial, não poderia dar diploma de bacharéis. Seu objetivo era propiciar a seus alunos o ensino de matérias julgadas necessárias à prática da profissão.

Em 1935, Anísio Teixeira, tentando mudar as estruturas educacionais do Rio de Janeiro, criou a Universidade do Distrito Federal. A UDF abrangia vários ramos do saber e da cultura, oferecendo cursos absolutamente inéditos, como administração e orientação escolares, auxiliares de medicina e técnicas de laboratório, diplomacia, estatística, serviço social, biblioteconomia, arquivo e museus, arquitetura paisagística, cinema, jornalismo e publicidade.

Mas a proposta da UDF para o ensino de jornalismo era, segundo José Marques de Melo (2000), distinta da preconizada pela $\mathrm{ABI}$ :

Trata-se de uma experiência educacional de jornalistas que se efetivou segundo padrões distintos daqueles preconizados pela ABI. Não configurava uma escola profissional para formar jornalistas em nível superior, mas de um curso universitário destinado a refletir sobre o fenômeno ascendente da cultura de massa, correlacionando duas atividades então imbricadas profissionalmente: o jornalismo e a publicidade (MELO, 2000, p.84).

A organização do curso foi entregue a Pedro da Costa Rego, editor-chefe do Correio da Manhã, que o estruturou a partir de um enfoque pedagógico mais semelhante ao modelo europeu (valorizando a formação humanística) do que ao norte-americano (mais técnico -profissional). A experiência, entretanto, durou pouco. A UDF foi desativada pelo governo, em 1939.

A estratégia desenvolvida pela ABI para concretizar a idéia da Escola de Jornalismo orientou-se no sentido de reivindicá-la perante o Estado, amarrando-a ao estatuto de regulamentação da profissão de jornalista.

Em novembro de 1938, Getúlio Vargas, através do Decreto-Lei n ${ }^{\circ}$ 910, dispôs sobre as condições de trabalho nas empresas jornalísticas e criou as escolas de jornalismo, estabelecendo a exigência do diploma para o exercício da profissão. A resistência patronal foi grande e o decreto nunca se efetivou. Além disso, o governo federal, apesar de assumir o compromisso de patrocinar cursos, transferia a responsabilidade para os governos estaduais, que nada faziam, tendo em vista sua situação econômica.

Em 1943, Vargas tentou novamente, através do Decreto-Lei no 5.480 de 13 de maio, criar o curso superior de jornalismo, desta vez não mencionando nada a respeito da obrigatoriedade do diploma para o exercício da profissão. O curso foi estruturado, no sistema de ensino universitário, subordinado à Faculdade de Filosofia, Ciências e Letras. O primeiro curso regular do País seria montando pela iniciativa privada, na Fundação Casper Líbero. ${ }^{18}$ Vinculado à Faculdade de Filosofia, Ciências e Letras São Bento, da Universidade Pontifícia Católica (PUC) de São Paulo, o curso foi autorizado pelo Decreto $\mathrm{n}^{\circ}$ 23.087, de 19 de maio de 1947 (RIBEIRO, 2007; BAHIA, 2000).

No Rio de Janeiro, o primeiro curso foi o da Faculdade Nacional de Filosofia da Universidade do Brasil (atual UFRJ). Criado em 1948, funcionou, conforme registra Ribeiro (2007, p.294), com professores indicados pela $\mathrm{ABI}$ e com recursos financeiros obtidos junto à Companhia de Cigarros Souza Cruz, da qual Herbert Moses era advogado. A turma inicial foi dispensada do vestibular e da prova de conclusão de estudos secundários.

Alguns professores das disciplinas específicas não possuíam formação profissional, mas eram jornalistas de renome. Dentre os primeiros professores, estavam Danton Jobim (incumbido das disciplinas de Ética e Técnica Jornalística), Celso Cunha (português), Josué de Castro (geografia), Celso Kelly (Sociologia), Fernando Tude de Souza e Marciel Dias Pequeno.

18 Cásper Líbero, diretor de A Gąeta de 1918 a 1943, deixou expressa em testamento a criação de um curso de jornalismo anexo ao seu jornal. O curso, segundo o testamento, deveria ser inteiramente gratuito (RIBEIRO, 2007, p. 294). 
Verifica-se a participação efetiva da ABI na formação dos profissionais, sendo que entre os primeiros professores da Universidade do Brasil estavam profissionais que atuaram como presidentes da associação, como Celso Kelly e Danton Jobim.

Até a década de 1960, prevaleceu no ensino de jornalismo um caráter humanístico: formação clássica, como no modelo europeu, dando preferência à filosofia, história e literatura, além de cultura geral. Dos anos 1960 aos anos 1970, predominou uma organização curricular baseada no modelo norte-americano: estudo da comunicação sob o enfoque funcionalista e empírico (RIBEIRO, 2007, p. 296).

Em 1965, a ABI apoiou a realização do Seminário Latino-americano de Ensino de Jornalismo e Comunicação (CIESPAL-ABI), evento que teve impacto significativo nos rumos do ensino em todo o país.

Outra relevante contribuição da $\mathrm{ABI}$ para o campo da comunicação, com conquista de reconhecimento nacional, foi a promoção no Rio de Janeiro, em 1971, do I Congresso Nacional de Comunicação. A iniciativa foi de Danton Jobim e o evento reuniu empresários, profissionais, acadêmicos e representantes governamentais de várias áreas e tendências.

Com o tempo, a questão da formação superior em jornalismo foi ganhando força no processo de profissionalização dos jornalistas. Somente nos anos 1980, os grandes jornais do Rio de Janeiro e São Paulo se renderam à necessidade de criar mecanismos de recrutamento e estágio para seleção de estudantes que se candidatavam ao exercício profissional (BAHIA, 2009, p.441). No país, no entanto, a questão sobre a exigência do diploma para exercer a profissão é polêmica. ${ }^{19}$

\section{Conclusões}

Este artigo teve como objetivo abordar a participação da ABI como instituição estimuladora da profissio-

19 Em junho de 2009, o Supremo Tribunal Federal (STF) derrubou a obrigatoriedade do diploma para atuar como jornalista sob, entre outros argumentos, de seu relator, na época presidente do STF, Gilmar Mendes, de que escritores atuaram na área sem serem formados nela. A Associação Nacional dos Jornais (ANJ) foi a favor, e a Federação Nacional dos Jornalistas (Fenaj), contra. Em agosto de 2012, foi aprovada pelo Senado a PEC 33/09, do senador Antônio Carlos Valadares (PSB/SE). Ela acrescenta dois parágrafos à Constituição: um que estabelece a privação da profissão aos diplomados em jornalismo e outro tira a exigência do diploma para colaboradores que, por sua vez, não poderão ter vínculo empregatício. A proposta vai passar ainda pela votação em primeiro e segundo turnos na Câmara dos Deputados. nalização do jornalista no país. Como vimos, a criação de associações e sindicatos fez parte do processo de legitimação e do fortalecimento do jornalismo como profissão e começou a partir da segunda metade do século XIX, nos Estados Unidos e na Europa. A profissionalização envolveu também a criação de cursos universitários e instituição de códigos deontológicos.

No Brasil, a criação da ABI, na primeira década do século XX, no Rio de Janeiro, foi uma consequência das transformações da imprensa dentro do contexto histórico daquele início de século. E representou um fato importante no processo de legitimação da profissão no país, que ganhou corpo nas décadas seguintes.

Uma das ações da ABI foi a promoção de congressos e palestras para esses profissionais. Já em sua fundação, estava clara a preocupação com o ensino do jornalismo, bandeira que seria retomada no I Congresso Brasileiro de Jornalistas, iniciativa da ABI, e que só se tornaria realidade em 1935, quando Anísio Teixeira instituiu a primeira cátedra de Jornalismo na Universidade do Distrito Federal, no Rio de Janeiro.

Ao longo de seus 104 anos a ABI, o primeiro organismo cooperativo dos jornalistas brasileiro, teve um papel significativo na construção da identidade profissional. Como lugar institucional e simbólico da defesa da profissão, a entidade, que faz parte do campo jornalístico, foi objeto de disputas, tensões de interesses entre seus próprios agentes, configurando-se não como uma instituição homogênea e monolítica da categoria, mas repleta de idiossincrasias. A ABI, contudo, contribuiu na percepção dos interesses próprios da categoria, tanto políticos quantos sociais, funcionando também como espaço de sociabilidade. E também para o fortalecimento do campo da comunicação no país.

\section{Referências:}

AZÊDO, Maurício. Nossa vocação: a liberdade. In: JORNAL DA ABI. Rio de Janeiro: ABI, 2008.

BARBOSA, Marialva. Os donos do Rio - imprensa, poder e público. Rio de Janeiro: Vício de Leitura, 2000, 257p.

. História cultural da imprensa - Brasil 1800-1900. Rio de Janeiro: Mauad X, 2010, 266p. 
. História cultural da imprensa - Brasil 1900-2000. Rio de Janeiro: Mauad X, 2007, 262p.

- Jornalismo e a construção de uma memória para sua história. In: BRAGANÇA, Aníbal \& MOREIRA, Sônia Virgínia (org). Comunicação, acontecimento e memória. São Paulo: Intercom, 2005, p.102-111.

BAHIA, Juarez. História da imprensa brasileira - Jornal, bistória e técnica. Rio de Janeiro: MauadX, $5^{\text {a }}$ edição, 2009, 446p.

BOURDIEU, Pierre. Campo do poder, campo intelectual e babitus de classe. In: A Economia das Trocas Simbólicas. São Paulo: Perspectiva, 1999, p. 183-202.

. Sobre a televisão. Rio de Janeiro: Jorge Zahar Editora, 1997, 143p.

ELLIOT, Philipe. Professional ideology and organizational change: The journalist Since 1800. In: Boyce, Curran e Wingate (Eds), Newspaper History: From the Seventeenth Century to the Present Day. London: a.: Sage Publications.

LENE, Hérica. Os jornais como lugares de memória e fontes de pesquisas. Trabalho apresentado no X Encontro dos Grupos de Pesquisas em Comunicação. In: Anais do Intercom - Sociedade Brasileira de Estudos Interdisciplinares da Comunicação XXXIII Congresso Brasileiro de Ciências da Comunicação - Caxias do Sul, RS - 2 a 6 de setembro de 2010.

LUCA, Tania Regina de. A grande imprensa na primeira metade do século XX. In: MARTINS, Ana Luiza \& LUCA, Tania $\mathrm{R}$ (orgs.). História da imprensa no Brasil. São Paulo: Editora Contexto, 2008, p.149-175.

MELO, José Marques. Costa Rego, o primeiro catedrático de jornalismo do Brasil. de 2000. Revista Intercom - Revista Brasileira de Ciências da Comunicação, Vol. XXIII, no 1 , janeiro/junho de 2000. Disponível em http://www.portcom.intercom.org.br/ojs-2.3.1-2/index.php/revistaintercom/article/view/548/517. Acesso em 9 de janeiro de 2012.

MOREIRA, Sônia Virgínia. Análise documental como método e como técnica. In: DUARTE, Jorge e BARROS, Antonio (org.) Métodos e Técnicas de Pesquisa em Comunicação. São Paulo: Editora Atlas, 2005, 380p.
MOREL, Edmar. A trincheira da liberdade - bistória da ABI. Rio de Janeiro: Record, 1985, 217p.

PEREIRA, Moacir. Gustavo de Lacerda: os sonhos de um repórter pobre. In: Jornal da ABI, Edição Especial Centenário, vol.1, no 328 , abril de 2008.

RIBEIRO, Ana Paula Goulart. Imprensa e história no Rio de Janeiro dos anos 1950. Rio de Janeiro: E-Papers, 2007, 362p.

SODRÉ, Nelson Werneck. História da imprensa no Brasil. Rio de Janeiro: Mauad, 1999, $4^{\text {a }}$ edição, 501p.

TRAQUINA, Nelson. Teorias do jornalismo: porque as noticias são como são. Vol. 1. Florianópolis: Insular, 2004, 223p. . Teorias do jornalismo - A tribo jornalistica - uma comunidade interpretativa transnacional. Vol. 2. Florianópolis: Insular, 2005, 213p.

ZELIZER, Barbie. Journalists as Interpretive Community. Critical Studies in Mass Comunications, vol.10., 1993.

Recebido: 03/08/2012

Aprovado: 06/11/2012
29

\section{Fonte html:}

Site da ABI - www.abi.org.br 